\title{
QUEEN'S
UNIVERSITY
BELFAST
}

\section{Antimicrobial susceptibility of non-fermenting Gram-negative pathogens isolated from cystic fibrosis patients}

Díez-Aguilar, M., Ekkelenkamp, M., Morosini, M-I., Merino, I., Caballero, J. D. D., Jones, M., van Westreenen, M., Tunney, M. M., Cantón, R., \& Fluit, A. C. (2018). Antimicrobial susceptibility of non-fermenting Gramnegative pathogens isolated from cystic fibrosis patients. International Journal of Antimicrobial Agents. https://doi.org/10.1016/j.ijantimicag.2018.09.001

Published in:

International Journal of Antimicrobial Agents

Document Version:

Peer reviewed version

Queen's University Belfast - Research Portal:

Link to publication record in Queen's University Belfast Research Portal

Publisher rights

(C) 2018 Elsevier B.V. and International Society of Chemotherapy. All rights reserved.

This manuscript version is made available under the CC-BY-NC-ND 4.0 license http://creativecommons.org/licenses/by-nc-nd/4.0/,which permits distribution and reproduction for noncommercial purposes, provided the author and source are cited

\section{General rights}

Copyright for the publications made accessible via the Queen's University Belfast Research Portal is retained by the author(s) and / or other copyright owners and it is a condition of accessing these publications that users recognise and abide by the legal requirements associated with these rights.

Take down policy

The Research Portal is Queen's institutional repository that provides access to Queen's research output. Every effort has been made to ensure that content in the Research Portal does not infringe any person's rights, or applicable UK laws. If you discover content in the Research Portal that you believe breaches copyright or violates any law, please contact openaccess@qub.ac.uk. 
Antimicrobial susceptibility of non-fermenting Gram-negative pathogens isolated from cystic fibrosis patients

María Díez-Aguilar, Miquel Ekkelenkamp, María-Isabel Morosini , Irene Merino , Juan de Dios Caballero, Mark Jones ,

Mireille van Westreenen, Michael M. Tunney, Rafael Cantón, Ad C. Fluit

PII:

DOI:

Reference:

To appear in:

Received date:

Revised date:

Accepted date:

\section{S0924-8579(18)30260-7}

https://doi.org/10.1016/j.jiantimicag.2018.09.001

ANTAGE 5535

International Journal of Antimicrobial Agents

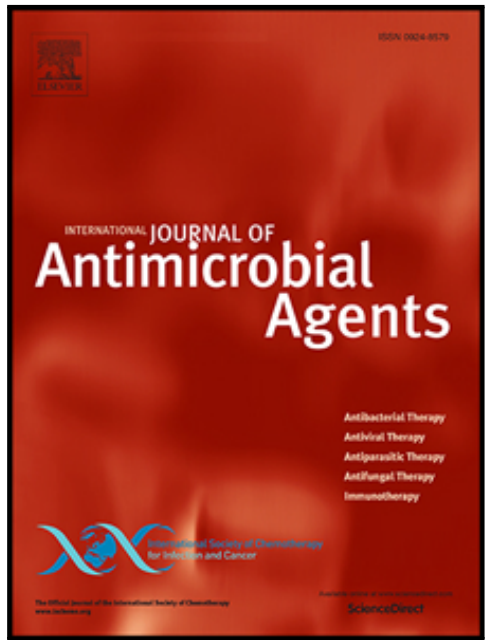

Please cite this article as: María Díez-Aguilar, Miquel Ekkelenkamp, María-lsabel Morosini, Irene Merino, Juan de Dios Caballero, Mark Jones, Mireille van Westreenen, Michael M. Tunney, Rafael Cantón, Ad C. Fluit, Antimicrobial susceptibility of non-fermenting Gram-negative pathogens isolated from cystic fibrosis patients, International Journal of Antimicrobial Agents (2018), doi: https://doi.org/10.1016/j.ijantimicag.2018.09.001

This is a PDF file of an unedited manuscript that has been accepted for publication. As a service to our customers we are providing this early version of the manuscript. The manuscript will undergo copyediting, typesetting, and review of the resulting proof before it is published in its final form. Please note that during the production process errors may be discovered which could affect the content, and all legal disclaimers that apply to the journal pertain. 


\section{Highlights}

- Non-fermenters other than $P$. aeruginosa are increasingly isolated from cystic fibrosis patients

- Cotrimoxazole is the most active compound against these pathogens

- All the microorganisms presented either a colistin $\mathrm{MIC}_{90}$ higher than $16 \mathrm{mg} / \mathrm{L}$

- No statistically significant differences in susceptibility rates between countries

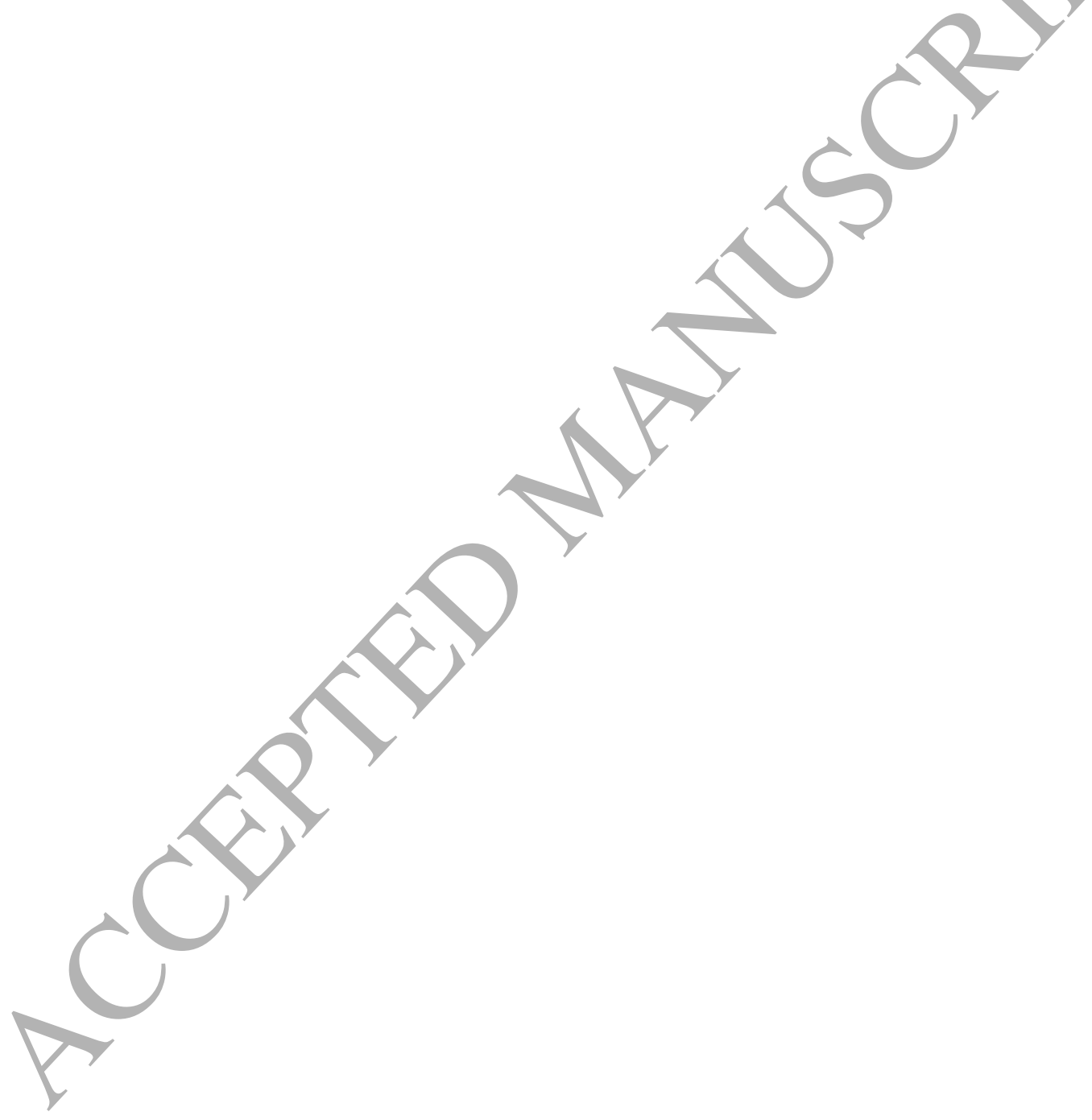




\title{
Antimicrobial susceptibility of non-fermenting Gram-negative pathogens isolated from cystic fibrosis patients
}

\author{
María Díez-Aguilar ${ }^{1,2}$, Miquel Ekkelenkamp ${ }^{3}$, María-Isabel Morosini ${ }^{1,2}$, Irene \\ Merino $^{1,2}$, Juan de Dios Caballero ${ }^{1,2}$, Mark Jones ${ }^{4}$, Mireille van Westreenen ${ }^{5}$, \\ Michael M. Tunney ${ }^{6}$, Rafael Cantón ${ }^{1,2}$, Ad C. Fluit $^{3}$
}

${ }^{1}$ Servicio de Microbiología, Hospital Universitario Ramón y Cajal and Instituto Ramón y Cajal de Investigación Sanitaria (IRYCIS), Madrid, Spain; ${ }^{2}$ Red Española de Investigación en Patología Infecciosa (REIPI), Madrid, Spain; ${ }^{3}$ Department of Medical Microbiology, University Medical Center Utrecht, Utrecht, The Netherlands. ${ }^{4}$ Basilea Pharmaceutica, Basel, Switzerland. ${ }^{5}$ Department of Medical Microbiology and Infectious Diseases, Erasmus MC, Rotterdam, The Netherlands. ${ }^{6}$ School of Pharmacy, Queen's University Belfast, Belfast, UK.

Address correspondence to: rafael.canton@salud.madrid.org

\begin{abstract}
Non-fermenting Gram negative bacteria are increasingly being cultured in respiratory samples from people with cystic fibrosis (CF). This study aimed to determine the susceptibility of clinical CF respiratory isolates from distinct geographical regions to a range of antimicrobials. A total of 286 isolates (106 Stenotrophomonas maltophilia, 100 Burkholderia spp., 59 Achromobacter spp., 12 Pandoraea spp. and 9 Ralstonia spp.) from The Netherlands, Northern Ireland, Spain, USA and Australia were tested. The $\mathrm{MIC}_{50}, \mathrm{MIC}_{90}$ and susceptibility categorization were determined. Cotrimoxazole was the most active compound for all the microorganisms $\left(\mathrm{MIC}_{50}=0.12-4 \mathrm{mg} / \mathrm{L}, \mathrm{MIC}_{90}=1-16 \mathrm{mg} / \mathrm{L}\right)$. For $S$. maltophilia, $47 \%$ and $62 \%$ of
\end{abstract}


isolates were susceptible to cotrimoxazole according to CLSI and EUCAST breakpoints, respectively. Ceftazidime presented a lower level of susceptibility $\left(35 \%, \mathrm{MIC}_{50}=32 \mathrm{mg} / \mathrm{L}\right.$, $\left.\mathrm{MIC}_{90}=256 \mathrm{mg} / \mathrm{L}\right)$. Tobramycin and colistin $\mathrm{MIC}_{90}$ were $>128 \mathrm{mg} / \mathrm{L}$ and $>16 \mathrm{mg} / \mathrm{L}$, respectively. Regarding Burkholderia isolates, $72 \%, 56 \%$ and $44 \%$ were susceptible to cotrimoxazole, ceftazidime and meropenem, respectively. For both ceftazidime and meropenem, the $\mathrm{MIC}_{50}$ and $\mathrm{MIC}_{90}$ values were within the intermediate or resistant category. The most active antibiotics for $A$. xylosoxidans were cotrimoxazole $\left(\mathrm{MIC}_{50}=2, \mathrm{MIC}_{90}=8 \mathrm{mg} / \mathrm{L}\right)$ and imipenem $\left(\mathrm{MIC}_{50}=2, \mathrm{MIC}_{90}=8 \mathrm{mg} / \mathrm{L}\right)$. Cotrimoxazole, imipenem, and ciprofloxacin were active against the 12 Pandoraea species $\left(\mathrm{MIC}_{50}=0.12-4 \mathrm{mg} / \mathrm{L}, \mathrm{MIC}_{90}=1-8 \mathrm{mg} / \mathrm{L}\right)$. Ciprofloxacin $\left(\mathrm{MCC}_{50}=4 \mathrm{mg} / \mathrm{L}\right)$ and cotrimoxazole $\left(\mathrm{MIC}_{50}=1 \mathrm{mg} / \mathrm{L}\right)$ were the only active antibiotics for Ralstonia spp. There were no statistically significant differences in susceptibility rates between countries.

Non-fermenting Gram-negative bacteria other than $P$. aeruginosa are potential pathogens in $\mathrm{CF}$ and cotrimoxazole has demonstrated to be the most active eompound against them.

Keywords: cystic fibrosis, Gram-negative non-fermenting bacteria, antimicrobial susceptibility

\section{Introduction}

Cystic fibrosis $(\mathrm{CF})$ patients are regularly colonized by opportunistic microorganisms. In adult patients, Pseudomonas aeruginosa is the main pathogen, but in recent years, other nonfermenting bacteria from different genera, such as Stenotrophomonas, Burkholderia, Achromobacter, Ralstonia, and Pandoraea, are increasingly being isolated [1-3]. This could be potentially due to the aggressive antimicrobial therapy used against $P$. aeruginosa, to the apparition of new techniques for the bacterial identification and improvement in life expectancy for people with CF [4].

In most cases, it has been reported that chronic colonization with these microorganisms is associated with a decline in pulmonary function; however, the pathogenic role of some of these species is not completely clear due to their coexistence with other pathogens including 
Staphylococcus aureus and P. aeruginosa [4]. Unlike P. aeruginosa, for which antimicrobial treatment is standardized, treatment protocols are not in place for these non-fermenting microorganisms and limited data is available regarding their susceptibility profiles. Studying the susceptibility patterns and the epidemiology of these microorganisms is essential to improve the management of CF patients.

The aim of this study was to determine the susceptibility of CF non-fermenting Gramnegative bacteria other than $P$. aeruginosa to a range of antimicrobials used in CF patients. This study is included within the objectives of the IMI-iABC European project which is mainly focused on the development of a new inhaled compound for CF patients.

\section{Material and Methods}

A total of 286 isolates recovered from respiratory samples of CF patients (2003-2016) from 5 different countries [Spain $(n=103)$, Northern Ireland $(n=98)$, The Netherlands $(n=82)$, USA $(n=2)$ and Australia $(n=1)$ ] were included in the study. Overall, 106 Stenotrophomonas maltophilia, 100 Burkholderia spp. (51 B. multivorans, 20 B. cenocepacia, 12 B. contaminans, 10 B. vietnamensis, 4 B. cepacia, 3 B. gladioli), 59 Achromobacter spp. (53 A. xylosoxidans, 4 Achromobacter sp., 2 A. insolitus), 12 Pandoraea spp. and 9 Ralstonia spp. isolates were studied. These bacteria were identified by MALDI-TOF MS; the identification was confirmed by whole genome sequencing. The species of Burkholderia were also confirmed by sequencing the recA gene as previously described [5].

MIC's were determined by standard ISO broth microdilution method with frozen panels (Trek Diagnostic Systems, Westlake, Ohio). The antibiotics and its concentration range tested were: ciprofloxacin (CIP, 0.03-32 mg/L), tobramycin (TOB, 0.125-128 mg/L), ceftazidime (CAZ, 0.25-256 mg/L), meropenem (MER, 0.06-64 mg/L), imipenem (IMI, 0.125-128 mg/L), aztreonam (AZT, 0.25-256 mg/L), cotrimoxazole (SXT, 0.06-32 mg/L), and colistin (COL, $0.25-16 \mathrm{mg} / \mathrm{L})$. 
$\mathrm{MIC}_{50}, \mathrm{MIC}_{90}$, and susceptibility categorization were assessed considering both EUCAST and CLSI breakpoints and the epidemiological cutoff (ECOFF) when available (Table 1, Table 2, Figure 1). To analyze the data by country, chi-square/Fisher test with the Bonferroni correction was used in order to compare susceptibility rates when an antibiotic breakpoint was available (statistically significant when $\mathrm{P}<0.016$ ). To reflect differences in mechanisms of antibiotic resistance between countries, $\mathrm{MIC}_{90}$ values were graphically represented (Figure S1).

Statistical analysis was performed using STATA statistical software for Windows (Data Analysis and Statistical Software, version 11.0). Isolates categorized as intermediate and susceptible were grouped for data analysis.

\section{Results}

$\mathrm{MIC}_{50}$ and $\mathrm{MIC}_{90}$ results for all the tested antibiotics and microorganisms are presented in Table 1. SXT was the most active compound for all the microorganisms, with a $\mathrm{MIC}_{50}$ range of 0.12-4 $\mathrm{mg} / \mathrm{L}$, and a $\mathrm{MIC}_{90}$ range of $1-16 \mathrm{mg} / \mathrm{L}$. All the microorganisms presented either a $\mathrm{COL} \mathrm{MIC}_{50}$ or $\mathrm{MIC}_{90}$ higher than $16 \mathrm{mg} / \mathrm{L}$.

Analysing S. maltophilia isolates, $47 \%$ and $62 \%$ of the isolates were susceptible to SXT when considering $\mathrm{CLSI}(\mathrm{S} \leq 2, \mathrm{R} \geq 4 \mathrm{mg} / \mathrm{L})$ and EUCAST $(\mathrm{S} \leq 4, \mathrm{R}>4 \mathrm{mg} / \mathrm{L})$ clinical breakpoints, respectively (Table 2, Figure 1). Coinciding with CLSI breakpoint, the EUCAST SXT ECOFF is $2 \mathrm{mg} / \mathrm{L}$, which means that $47 \%$ of the isolates were included in the wild-type population. CAZ presented a lower level of susceptibility (S 35\%; I 6\%; R 59\%), placing both, the $\mathrm{MIC}_{50}$ $(32 \mathrm{mg} / \mathrm{L})$ and $\mathrm{MIC}_{90}(256 \mathrm{mg} / \mathrm{L})$ within the resistant population (Table 2, Figure 1). There are not defined clinical breakpoints for CIP, but the $\mathrm{MIC}_{50}$ value $(4 \mathrm{mg} / \mathrm{L})$ was close to the EUCAST modal value $(2 \mathrm{mg} / \mathrm{L})$ in $S$. maltophilia. For both tobramycin and colistin, $\mathrm{MIC}_{90}$ values were high (>128 mg/L, >16 mg/L, respectively). 
Considering all the Burkholderia species, according to CLSI breakpoints, 72\%, 56\% and $44 \%$ of the isolates were susceptible to $\mathrm{SXT}(\mathrm{S} \leq 2, \mathrm{R} \geq 4 \mathrm{mg} / \mathrm{L}), \mathrm{CAZ}(\mathrm{S} \leq 8 \mathrm{mg} / \mathrm{L}, \mathrm{I}=16$ $\mathrm{mg} / \mathrm{L}, \mathrm{R} \geq 32 \mathrm{mg} / \mathrm{L}$ ) and MER ( $\mathrm{S} \leq 4 \mathrm{mg} / \mathrm{L}, \mathrm{I}=8 \mathrm{mg} / \mathrm{L}, \mathrm{R} \geq 16 \mathrm{mg} / \mathrm{L}$ ), respectively (Table 2 ). For both $\mathrm{CAZ}$ and MER, the $\mathrm{MIC}_{50}$ and the $\mathrm{MIC}_{90}$ were included within the intermediate or resistant category. Although the $\mathrm{MIC}_{90}$ was lower for MER (32 mg/L) than for CAZ (128 mg/L).

Analysing the antimicrobial activity of the different species of the Burkholderia cepacia complex (51 B. multivorans, 20 B. cenocepacia, 12 B. contaminans, 10 B. vietnamensis and 4 B. cepacia), the lowest CAZ $\mathrm{MIC}_{90}$ was obtained for B. vietnamensis $(16 \mathrm{mg} / \mathrm{L}$ vs. $64-256 \mathrm{mg} / \mathrm{L})$. B. vietnamensis also presented lower $\mathrm{IMI} \mathrm{MIC}_{50}(1 \mathrm{mg} / \mathrm{L})$ and $\mathrm{MIC}_{90}(32 \mathrm{mg} / \mathrm{L})$ values, than the other species [(IMI $\left.\mathrm{MIC}_{50}(32-64 \mathrm{mg} / \mathrm{L}), \mathrm{MIC}_{90} 128-256 \mathrm{mg} / \mathrm{L}\right)$ range]. The susceptibility profiles for the rest of the antibiotics were similar for all the Burkholderia species.

Neither CLSI nor EUCAST have established specific clinical breakpoints for Achromobacter spp. Different Achromobacter species were not analysed separately as the majority of isolates tested were A. xylosoxidans (91.4\%). After SXT, the most active antibiotic was imipenem ( $\mathrm{IMI} \mathrm{MIC}_{50}=2, \mathrm{MIC}_{90}=8 \mathrm{mg} / \mathrm{L}$ ). The COL MIC had a bimodal distribution, with a first modal value of $1 \mathrm{mg} / \mathrm{L}$ and a second modal value of $32 \mathrm{mg} / \mathrm{L}$.

SXT, IMI, and CIP were active against the 12 Pandoraea isolates tested, with a range of $\mathrm{MIC}_{50}$ and $\mathrm{MIC}_{90}$ values of $0.12-4 \mathrm{mg} / \mathrm{L}$ and $1-8 \mathrm{mg} / \mathrm{L}$, respectively. Analysing Ralstonia spp., a high level of antimicrobial resistance was observed, with CIP $\left(\mathrm{MIC}_{50}=4 \mathrm{mg} / \mathrm{L}\right)$ and SXT $\left(\mathrm{MIC}_{50}=1 \mathrm{mg} / \mathrm{L}\right)$ as the only active antibiotics.

For S. maltophilia, there were no statistically significant differences between countries in CAZ and SXT susceptibility (p>0.016) as shown in Figure $\mathrm{S} 1$, where the antibiotic $\mathrm{MIC}_{90}$ values are reported for the separate countries.

Considering the origin of Burkholderia species, B. multivorans was most frequently isolated species in Northern Ireland and The Netherlands (48.6\% and 68.6\%, respectively) while in Spain it was B. contaminans (39.3\%). A lower rate of MER susceptibility was observed for 
Burkholderia isolates from Northern Ireland (54.3\%) compared with those from Spain (78.6\%) and The Netherlands $(74.3 \%)$ although it was not statistically significant $(\mathrm{p}=0.02)$. Curiously similar MER $\mathrm{MIC}_{90}$ values were observed between these countries $(4-8 \mathrm{mg} / \mathrm{L})$ (Figure S1). There were no statistically significant differences in CAZ and SXT susceptibility by country, although $\mathrm{CAZ} \mathrm{MIC}_{90}$ for isolates from Spain was 2-3 dilutions lower than the $\mathrm{CAZ} \mathrm{MIC}_{90}$ found in The Netherlands and Northern Ireland. The SXT MIC 90 for isolates from Northern Ireland was 2-3 dilutions lower than that found from Spain and The Netherlands.

For Achromobacter spp., SXT $\mathrm{MIC}_{90}$ value reported from Northern Ireland was 4 dilutions lower than that from Spain.

\section{Discussion}

Non-fermentative Gram-negative bacteria other than P. aeruginosa, such as Burkholderia cepacia complex, Stenotrophomonas, Achromobacter, Ralstonia, and Pandoraea, are increasingly isolated in respiratory samples from $\mathrm{CF}$ patients. These microorganisms are in general intrinsically resistant to multiple antibiotics and treatment guidelines are not yet available, so clinicians judge each patient individually considering the in vitro antimicrobial susceptibility reports and clinical outcome after therapy. Furthermore, the available clinical breakpoints are intended for systemic therapy and may not be adequate for inhaled therapy. Inhaled therapy has the potential to achieve high pulmonary concentrations and may be able to inhibit microorganisms with MICs above the breakpoints for systemic therapy [6].

Some studies have defined S. maltophilia as a colonizer, while others demonstrated that this microorganism is capable of causing a deterioration in pulmonary function $[7,8]$. Nevertheless, the presence of S. maltophilia cannot be ignored in some patients, as it is associated with an increased risk of pulmonary exacerbations, the need for lung transplantation, and death [9]. Generally, SXT is the antibiotic of choice, but during the last years increasing resistance rates are being reported in $\mathrm{CF}$ patients ranging from $16 \%$ to $45 \%[2,3,10,11]$. In our 
study, the SXT resistance rate was 38\% and 53\% following EUCAST and CLSI guidelines, respectively. Comparison between EUCAST MIC distribution and that obtained in this study shows a clear displacement of the latter to higher concentrations. In fact, the majority of non-CF S. maltophilia isolates are susceptible to SXT (global rate of less than 10\% resistance) [12]. Although CAZ and fluoroquinolones are considered as options for S. maltophilia, high resistance rates of both compounds are also increasingly being reported. In our study, approximately $60 \%$ of the isolates were CAZ resistant, a rate similar to that previously published (80\% [13], 70\% [2]). Newer fluoroquinolones, such as moxifloxacin may have a better activity against $S$. maltophilia than CIP $\left(\mathrm{MIC}_{90}=32 \mathrm{mg} / \mathrm{L}\right.$ in this study) [12].

The isolation of Burkholderia spp. is particularly worrying in CF patients, as it is related to a rapid decline in pulmonary function and to a high morbidity and mortality [14]. Similar to S. maltophilia, SXT is the antibiotic of choice for Burkholderia spp., but combinations are frequently used. A lower SXT resistance rate (28\%) was observed than for S. maltophilia. Resistance rates for MER and CAZ were more than $30 \%$ for both antibiotics.

The clinical relevance of the isolation of species of Achromobacter in the sputum of $\mathrm{CF}$ patients is unclear. Some studies have demonstrated that its presence is associated with a risk of pulmonary exacerbation but not with a worsened long-term prognosis [15]. Also, Achromobacter isolated from people with CF seem to be more virulent than those isolated from other sources [16]. The most active agents for Achromobacter were SXT and IMI. In contrast to previously published data, MER was less active than IMI [16]. CAZ, COL, and TOB have been considered adequate for inhalation therapy [17]; however, in this study, these antibiotics presented high $\mathrm{MIC}_{90}$ values.

The prevalence of Ralstonia and Pandoraea infection in CF is low. The pathogenic role of Pandoraea spp. appears to be due to the increase in the production of pro-inflammatory cytokines, but the clinical impact is still uncertain[18]. Although only a limited number of Ralstonia and Pandoraea isolates were tested, our results demonstrated that IMI and SXT had 
good activity against Pandoraea and CIP and SXT against Ralstonia. These observations agree with previously published data $[4,18,19]$.

As the scope of the initial research of the iABC project was to analyze $P$. aeruginosa susceptibility, a limitation of our study is that some antibiotics suitable for non-fermenters other than $P$. aeruginosa were not included in the MIC panels. However, the findings of our study provide insights about the epidemiology and susceptible patterns of these microorganisms from different geographical regions.

In conclusion, non-fermenting Gram-negative bacteria other than P. aeruginosa are potential pathogens increasingly being isolated from respiratory samples of CF patients. Little is known about their epidemiology, clinical management and antimicrobial susceptibility. We provide susceptibility testing data to different antimicrobials to better define their antimicrobial susceptibility profile. Considering available clinical breakpoints, SXT has demonstrated to be the most active compound against all isolates tested.

\section{Acknowledgments}

María Díez-Aguilar was partially supported by the Innovative Medicines Initiative (IMI)European Commission-funded project (iABC grant 115721-2) and Fundación Francisco Soria Melguizo (Madrid. Spain). The content and scientific background of this work were also supported by Plan Nacional de I+D+i 2013- 2016 and Instituto de Salud Carlos III, Subdirección General de Redes y Centros de Investigación Cooperativa, Ministerio de Economía, Industria y Competitividad, Spanish Network for Research in Infectious Diseases (REIPI RD12/0015/0004; REIPI RD16/0016/0011)- cofinanced by European Development Regíonal Fund “A way to achieve Europe" (ERDF), Operative program Intelligent Growth 2014- 2020. 


\section{Declarations}

Funding: The research leading to these results has received support from the Innovative Medicines Initiative Joint Undertaking under grant agreement no [115721-2], resources of which are composed of financial contribution from the European Union's Seventh Framework Programme (FP7/2007-2013) and EFPIA companies in kind contribution; Fundacion Francisco Soria Melguizo and Plan Nacional de I + D + i 2013-2016; Instituto de Salud Carlos III REIPI.

Competing Interests: The authors have no conflict of interests.

Ethical Approval: Not required

\section{References}

[1] Magni A, Giordano A, Mancini C, Pecoraro C, Văresi P, Quattrucci S, et al. Emerging cystic fibrosis pathogens: Incidence and antimicrobial resistance. New Microbiol 2007;30:59-62.

[2] de Dios Caballero J, del Campo R, Royuela A, Solé A, Máiz L, Olveira C, et al. Bronchopulmonary infection-colonization patterns in Spanish cystic fibrosis patients: Results from a national multicenter study. J Cyst Fibros 2016;15:357-65. doi:10.1016/j.jcf.2015.09.004.

[3] Valenza G, Tappe D, Turnwald D, Frosch M, König C, Hebestreit H, et al. Prevalence and antimicrobial susceptibility of microorganisms isolated from sputa of patients with cystic fibrosis. J Cyst Fibros 2008;7:123-7. doi:10.1016/j.jcf.2007.06.006.

[4] Green H, Jones A. The microbiome and emerging pathogens in cystic fibrosis and noncystic fibrosis bronchiectasis. Semin Respir Crit Care Med 2015;36:225-35. doi:10.1055/s-0035-1546752.

[5] Spilker T, Baldwin A, Bumford A, Dowson CG, Mahenthiralingam E, LiPuma JJ. 
Expanded multilocus sequence typing for Burkholderia species. J Clin Microbiol 2009;47:2607-10. doi:10.1128/JCM.00770-09.

[6] Ratjen A, Yau Y, Wettlaufer J, Matukas L, Zlosnik JEA, Speert DP, et al. In vitro efficacy of high-dose tobramycin against Burkholderia cepacia complex and Stenotrophomonas maltophilia isolates from cystic fibrosis patients. Antimicrob Agents Chemother 2015;59:711-3. doi:10.1128/AAC.04123-14.

[7] Waters V, Yau Y, Prasad S, Lu A, Atenafu E, Crandall I, et al. Stenotrophomonas maltophilia in cystic fibrosis: Serologic response and effect on lung disease, Am J Respir Crit Care Med 2011;183:635-40. doi:10.1164/rccm.201009-1392OC.

[8] Goss CH, Mayer-Hamblett N, Aitken ML, Rubenfeld GD, Ramsey BW. Association between Stenotrophomonas maltophilia and lung function in cystic fibrosis. Thorax 2004;59:955-9. doi:10.1136/thx.2003.017707.

[9] Waters V, Atenafu EG, Lu A, Yau Y, Tullis E, Ratjen F. Chronic Stenotrophomonas maltophilia infection and mortality or lung transplantation in cystic fibrosis patients. $\mathbf{J}$ Cyst Fibros 2013;12:482-6. doi:10.1016/j.jcf.2012.12.006.

[10] Cantón R, Valdezate S, Vindel A, Sánchez Del Saz B, Maíz L, Baquero F. Antimicrobial susceptibility profile of molecular typed cystic fibrosis Stenotrophomonas maltophilia isolates and differences with noncystic fibrosis isolates. Pediatr Pulmonol 2003;35:99107. doi:10.1002/ppul.10216.

[11] San Gabriel P, Zhou J, Tabibi S, Chen Y, Trauzzi M, Saiman L. Antimicrobial susceptibility and synergy studies of Stenotrophomonas maltophilia isolates from patients with cystic fibrosis. Society 2004;48:168-71. doi:10.1128/AAC.48.1.168.

[12] Chang Y-T, Lin C-Y, Chen Y-H, Hsueh P-R. Update on infections caused by Stenotrophomonas maltophilia with particular attention to resistance mechanisms and therapeutic options. Front Microbiol 2015;6:1-20. doi:10.3389/fmicb.2015.00893. 
[13] Wei C, Ni W, Cai X, Zhao J, Cui J. Evaluation of trimethoprim/sulfamethoxazole (SXT), minocycline, tigecycline, moxifloxacin, and ceftazidime alone and in combinations for SXT-susceptible and SXT-resistant Stenotrophomonas maltophilia by in vitro time-kill experiments. PLoS One 2016;11:1-9. doi:10.1371/journal.pone.0152132.

[14] Regan K, Jayesh B. Eradication therapy for Burkholderia cepacia complex in people with cystic fibrosis. Cochrane Database Syst Rev 2016. doi:10.1002/14651858.CD009876.pub3

[15] Edwards BD, Greysson-Wong J, Somayaji R, Waddell B, Whelan FJ, Storey DG et al. Prevalence and Outcomes of Achromobacter Species Infections in Adults with Cystic Fibrosis: a North American Cohort Study. J Clin Microbiol 2017;55:2074-85. doi: 10.1128/JCM.02556-16

[16] Filipic B, Malesevic M, Vasiljevic Z, Lukic J, Noyovic K, Kojic M, et al. Uncovering differences in virulence markers associated with Achromobacter species of CF and nonCF Origin. Front Cell Infect Microbiol 2017;7. doi:10.3389/fcimb.2017.00224.

[17] Wang M, Ridderberg W, Hansen CR, Høiby N, Jensen-Fangel S, Olesen H V., et al. Early treatment with inhaled antibiotics postpones next occurrence of Achromobacter in cystic fibrosis. J Cyst Fibros 2013;12:638-43. doi:10.1016/j.jcf.2013.04.013.

[18] Martina PF, Martínez M, Frada G, Alvarez F, Leguizamón L, Prieto C, et al. First time identification of Pandoraea sputorum from a patient with cystic fibrosis in Argentina: A case report. BMC Pulm Med 2017;17:1-5. doi:10.1186/s12890-017-0373-y.

[19] Prior AR, Gunaratnam C, Humphreys H. Ralstonia species - do these bacteria matter in cystic fibrosis? Paediatr Respir Rev 2017;23:78-83. doi:10.1016/j.prrv.2016.09.005. 
Table 1. MIC 50 and $\mathrm{MIC}_{90}$ results for the tested antibiotics and microorganisms

\begin{tabular}{|c|c|c|c|c|c|c|c|c|}
\hline & $\begin{array}{c}\mathrm{CAZ} \\
\mathrm{mg} / \mathrm{L}\end{array}$ & MER & IMI & AZT & CIP & TOB & COL & SXT \\
\hline \multicolumn{9}{|c|}{$\begin{array}{l}\text { S. maltophilia } \\
(\mathrm{n}=106)\end{array}$} \\
\hline $\mathrm{MIC}_{50}$ & 32 & $>64$ & $>128$ & $>256$ & 4 & 64 & 1 & 4 \\
\hline $\mathrm{MIC}_{90}$ & 256 & $>64$ & $>128$ & $>256$ & 32 & $>128$ & $>16$ & 16 \\
\hline \multicolumn{9}{|c|}{$\begin{array}{l}\text { Burkholderia spp. } \\
(\mathrm{n}=100)\end{array}$} \\
\hline $\mathrm{MIC}_{50}$ & 8 & 8 & 32 & 128 & 4 & & $>16$ & 2 \\
\hline $\mathrm{MIC}_{90}$ & 128 & 32 & 128 & $>256$ & 64 & $>128$ & $>16$ & 8 \\
\hline \multicolumn{9}{|c|}{$\begin{array}{l}\text { Achromobacter spp. } \\
(n=59)\end{array}$} \\
\hline $\mathrm{MIC}_{50}$ & 8 & 2 & 2 & $>256$ & 8 & 128 & 2 & 0,5 \\
\hline $\mathrm{MIC}_{90}$ & 128 & 32 & 8 & $>256$ & 32 & $>128$ & $>16$ & 8 \\
\hline \multicolumn{9}{|c|}{$\begin{array}{l}\text { Pandoraea spp. } \\
(n=12)\end{array}$} \\
\hline $\mathrm{MIC}_{50}$ & 128 & $>64$ & 2 & $>256$ & 4 & 128 & $>16$ & 0,12 \\
\hline $\mathrm{MIC}_{90}$ & 256 & $>64$ & 8 & $>256$ & 8 & $>128$ & $>16$ & 1 \\
\hline \multicolumn{9}{|c|}{$\begin{array}{l}\text { Ralstonia spp. } \\
(\mathrm{n}=9)\end{array}$} \\
\hline $\mathrm{MIC}_{50}$ & 16 & 128 & 32 & $>256$ & 4 & 128 & $>16$ & 1 \\
\hline
\end{tabular}

CAZ (ceftazidime), MER (meropenem), IMI (imipenem), AZT (aztreonam), CIP (ciprofloxacin), TOB (tobramycin), COL (colistin), SXT (cotrimoxazole).

Table 2. Clinical susceptibility of S. maltophilia and Burkholderia spp. to ceftazidime, meropenem and cotrimoxazole

\begin{tabular}{|c|c|c|c|c|c|c|c|c|c|}
\hline & & \multicolumn{2}{|l|}{ CAZ } & \multicolumn{3}{|c|}{ MER } & \multicolumn{3}{|c|}{ SXT } \\
\hline & (\%) & $\mathbf{S}$ & $\mathbf{I}$ & $\mathbf{R}$ & $\mathbf{S}$ & $\mathbf{I}$ & $\mathbf{R}$ & $\mathbf{S}$ & $\mathbf{R}$ \\
\hline \multirow[t]{2}{*}{ CLSI } & S. maltophilia & 35 & 6 & 59 & - & - & - & 47 & 53 \\
\hline & Burkholderia spp. & 56 & 5 & 39 & 44 & 25 & 31 & 72 & 28 \\
\hline \multirow[t]{2}{*}{ EUCAST } & S. maltophilia & $-{ }^{a}$ & - & - & - & - & & 62 & 38 \\
\hline & Burkholderia spp. & - & - & - & 2 & 98 & - & - & - \\
\hline
\end{tabular}

${ }^{\mathrm{a}}$ Clinical breakpoints have not been defined 
S. maltophilia

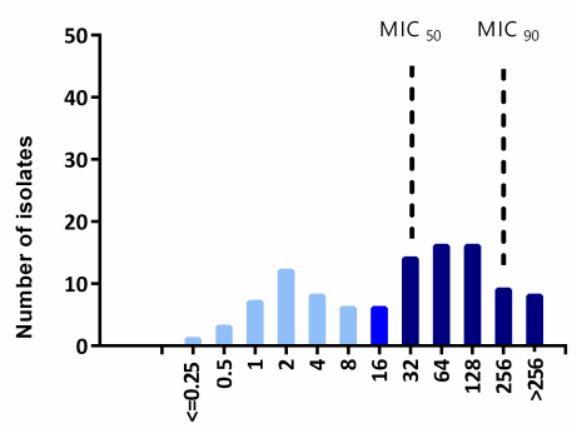

MIC CAZ (mg/L)

Burkholderia spp.

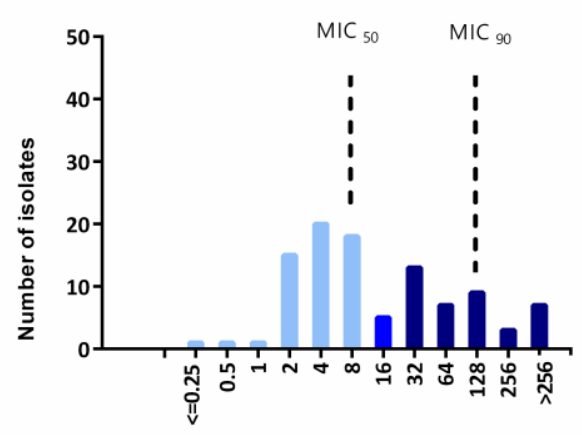

$\operatorname{MIC~CAZ~(mg/L)~}$

Burkholderia spp.

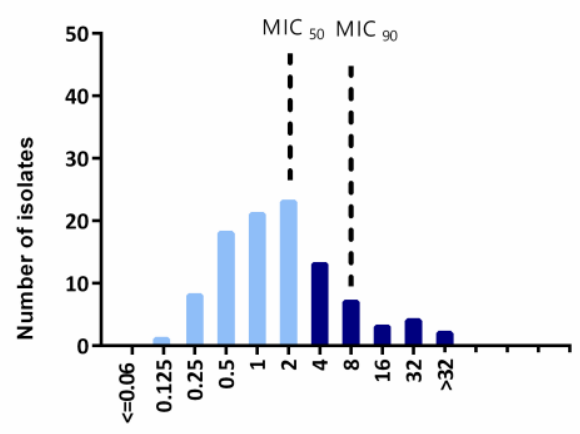

MIC SXT (mg/L)
S. maltophilia

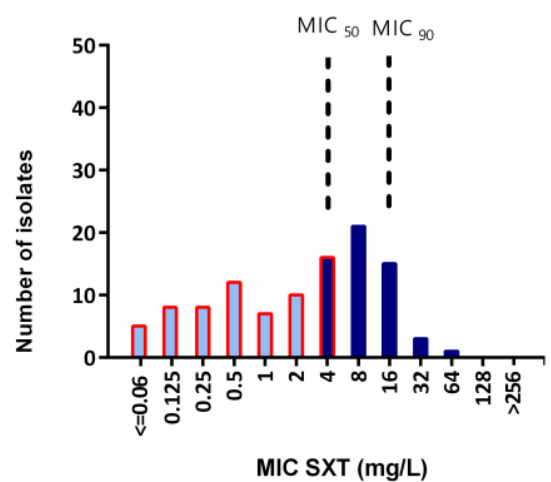

Burkholderia spp.

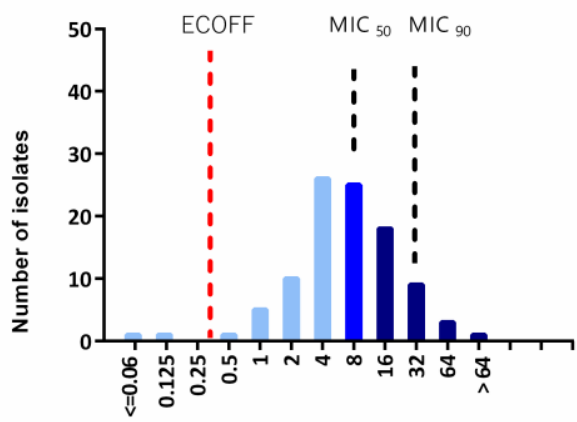

MIC MER (mg/L)

Figure 1. Ceftazidime, cotrimoxazole and meropenem MIC distribution for S. maltophilia and Burkholderia spp. Susceptibility categorization was performed using the CLSI guidelines (Susceptible: light blue, Intermediate: medium-light blue and resistant: dark blue). For S. maltophilia and cotrimoxazole, EUCAST susceptible isolates are marked in red. In the case of Burkholderia and meropenem, the ECOFF is represented by a discontinuous red line. 